\title{
Proteasome inhibition by bortezomib does not translate into efficacy on two malignant glioma xenografts
}

\author{
MARIANNE LABUSSIERE ${ }^{1 *}$, SOPHIE PINEL ${ }^{1 *}$, SUZANNE DELFORTRIE $^{1}$, \\ FRANÇOIS PLENAT $^{1,2}$ and PASCAL CHASTAGNER ${ }^{1,3}$ \\ ${ }^{1}$ EA 4001 Nancy Université, Avenue de la Forêt de Haye, BP184; ${ }^{2}$ Service d'Anatomie et de Cytologie \\ Pathologiques, Hôpital de Brabois CHRU Nancy; ${ }^{3}$ Service d'Oncologie Pédiatrique, \\ Hôpital d'Enfants CHRU Nancy, Rue du Morvan, F-54500 Vandoeuvre-les-Nancy, France
}

Received May 15, 2008; Accepted July 7, 2008

DOI: 10.3892/or_00000142

\begin{abstract}
Bortezomib and other proteasome inhibitors have demonstrated an interesting antitumor activity against glioma cell lines. The present study aimed to evaluate the cytotoxic potential of bortezomib in vivo on two human malignant glioma xenografts using doses relevant to clinical practice. The TCG3 and U87 malignant glioma xenografts were heterotopically implanted onto nude mice. Bortezomib effects were evaluated using the three different doses of $0.25,0.45$ and $0.90 \mathrm{mg} / \mathrm{kg}$. Proteasome chymotrypsin-like activity was measured by a fluorimetric method. Analysis of the cell cycle distribution was performed after propidium iodide staining. The apoptotic rate and proliferative index were determined by an immunohistochemical detection of cleaved caspase-3 and Ki-67, respectively. Our data showed that bortezomib induced a dose-dependent inhibition of proteasome chymotrypsin-like activity in the two glioma models. Maximal inhibition was achieved $24 \mathrm{~h}$ after drug injection and was $\sim 30 \%$ of basal proteasome activity. However, this effect did not induce any increase in the apoptotic rate and did not modify cell cycle distribution. At the maximal dose tested $(0.90 \mathrm{mg} / \mathrm{kg})$, bortezomib did not show any growth delay as compared to untreated tumors, in either of the xenograft models. In conclusion, our study is the first to demonstrate that bortezomib, at a clinically relevant dose, did not have any effect on the apoptosis and proliferation of malignant gliomas in vivo. These results contrast with the promising preclinical data obtained in vitro with this drug and
\end{abstract}

Correspondence to: Dr Sophie Pinel, EA 4001 Radiopotentialisation: de la préclinique à la clinique, Faculté de Médecine, 9 avenue de la Forêt de Haye, BP184, F-54500 Vandoeuvre-lesNancy, France

E-mail: pinel.sophie@aliceadsl.fr

${ }^{*}$ Contributed equally

Key words: bortezomib, malignant glioma, xenograft models emphasize the importance of performing preclinical studies on animal models, in conditions close to clinical settings.

\section{Introduction}

Malignant gliomas are the most common primary central nervous system tumors in adults and are uniformly fatal despite aggressive therapy. Currently, standard-of-care for glioblastoma consists of surgical resection and ionizing irradiation concomitantly delivered with temozolomide, followed by adjuvant temozolomide (1). Although many chemotherapeutic regimens have been proposed, the median survival for patients with newly diagnosed malignant glioma is $8-15$ months and has not significantly increased in the last three decades. Only $3 \%$ of patients are still alive 5 years after diagnosis (2). The failure of current therapies can be linked to multiple factors including inherent tumor resistance to standard chemo- and radiotherapy, early invasion of tumor cells into normal brain preventing complete surgical resection, and limitations of drug delivery due to the blood-brain barrier. Thus, new treatment concepts or cytotoxic drugs are urgently needed to improve patient outcome.

The ubiquitin-proteasome pathway plays an essential role in the degradation of most short- and long-lived intracellular proteins in eukaryotic cells. At the heart of this degradative pathway is the $26 \mathrm{~S}$ proteasome, an adenosine triphosphatedependent multicatalytic protease (3). Proteolytic degradation of damaged, oxidized, or misfolded proteins is part of the housekeeping role for the $26 \mathrm{~S}$ proteasome. In addition, the 26S proteasome plays a vital role in degrading regulatory proteins that govern the cell cycle, transcriptional factor activation, apoptosis and cell trafficking $(3,4)$. Proteasome inhibitors represent a relatively new class of antineoplastic agents that act by interfering with the catalytic $20 \mathrm{~S}$ core of the proteasome, thereby preventing the elimination of diverse cellular proteins targeted for degradation $(5,6)$. Bortezomib is the first-in-class proteasome inhibitor that had reached clinical trials and is currently indicated in the treatment of relapsed/ recurrent multiple myeloma patients (7). Initial preclinical screening by the National Cancer Institute revealed that bortezomib potently inhibited cell proliferation in a broad range of tumor types, including glioblastoma cell lines (8). 
Such results have been confirmed by recent studies reporting on the effects of bortezomib on human glioma cell lines $(9,10)$. Among these studies, Yin et al (10) have demonstrated that bortezomib induced a G2/M cell cycle arrest associated with an increase of apoptotic cells in the two glioma cell lines and primary glioblastoma explants.

Thus, the present study aimed to evaluate the effect of bortezomib in vivo on two human malignant glioma xenografts using regimens close to clinical practice.

\section{Materials and methods}

Animals and tumors. Athymic NCr/Sed nude (nu/nu) female mice, 7-8 weeks of age, were purchased from Charles River ${ }^{\circledR}$ (St. Germain sur l'Arbresle, France) and housed for 1 week before experimentation. For all experiments, animals had access to food and water ad libitum. Animal procedures were performed according to institutional and national guidelines (EC directive 86/609/CEE, French decree no. 87-848). Surgical procedures were carried out under general anesthesia obtained by intraperitoneal (i.p.) injection of xylazine $8 \mathrm{mg} / \mathrm{kg}$ and ketamine $90 \mathrm{mg} / \mathrm{kg}$.

Tumor xenografts were obtained as previously described (11). Briefly, the first model (TCG3) was derived from an anaplastic oligodendroglioma (according to WHO grading, 2007) of a 58-year-old woman. Samples of the patient tumor were directly subcutaneously (s.c.) transplanted into the hind leg of mice, providing the first xenografts. The second model (U87) was originally obtained by subcutaneously injecting a suspension of U87 human malignant glioma cells $\left(10^{6}\right.$ cells in $0.1 \mathrm{ml} 0.9 \% \mathrm{NaCl}$ ), purchased from the American Type Culture Collection $(H T B-14)$, into the hind legs of mice. TCG3 and U87 glioma models were then maintained in vivo by sequential passages of tumor fragments in nude mice. Tumor samples are regularly analyzed to ensure the genetic stability of the xenografts.

Treatment procedures. Treatments started when tumors reached a volume of $250 \pm 50 \mathrm{~mm}^{3}$ (V0). Mice were randomly assigned into different groups. In the CTRL group, mice were not treated. Bortezomib (BTZ) was administered intravenously (i.v.) at different doses $(0.25,0.45$ or $0.90 \mathrm{mg} / \mathrm{kg})$. BTZ was provided by Janssen-Cilag (Issy les Moulineaux, France) and was prepared according to the manufacturer's instructions.

$20 S$ proteasome activity. The effects of bortezomib on proteasome chymotrypsin-like activity were measured as previously described $(8,12)$. Briefly, at a selected time point after i.v. bortezomib administration, tumor samples were collected and frozen at $-80^{\circ} \mathrm{C}$. After thawing, tumor samples were weighed and homogenized in $2 \mathrm{ml} / \mathrm{g}$ lysis buffer $(50 \mathrm{mM}$ Tris $\mathrm{HCl} ; 2 \mathrm{mM}$ DTT; $5 \mathrm{mM} \mathrm{MgCl}_{2}$ and $250 \mathrm{mM}$ sucrose). After centrifugation $\left(10,000 \mathrm{~g}\right.$ for $10 \mathrm{~min}$ at $\left.4^{\circ} \mathrm{C}\right)$, supernatants were collected and the protein concentration was measured. Protein $(100 \mu \mathrm{g})$ from each sample was diluted in lysis buffer to a final volume of $100 \mu 1$ and the fluorogenic peptide substrate (succinyl-Leu-Leu-Val-Tyr-AMC, Sigma) was added at a final concentration of $100 \mu \mathrm{M}$. The reaction mixtures were incubated at $37^{\circ} \mathrm{C}$ for $2 \mathrm{~h}$. Free 7-amido-4-methylcoumarin (AMC) liberated by the substrate hydrolysis was quantified on

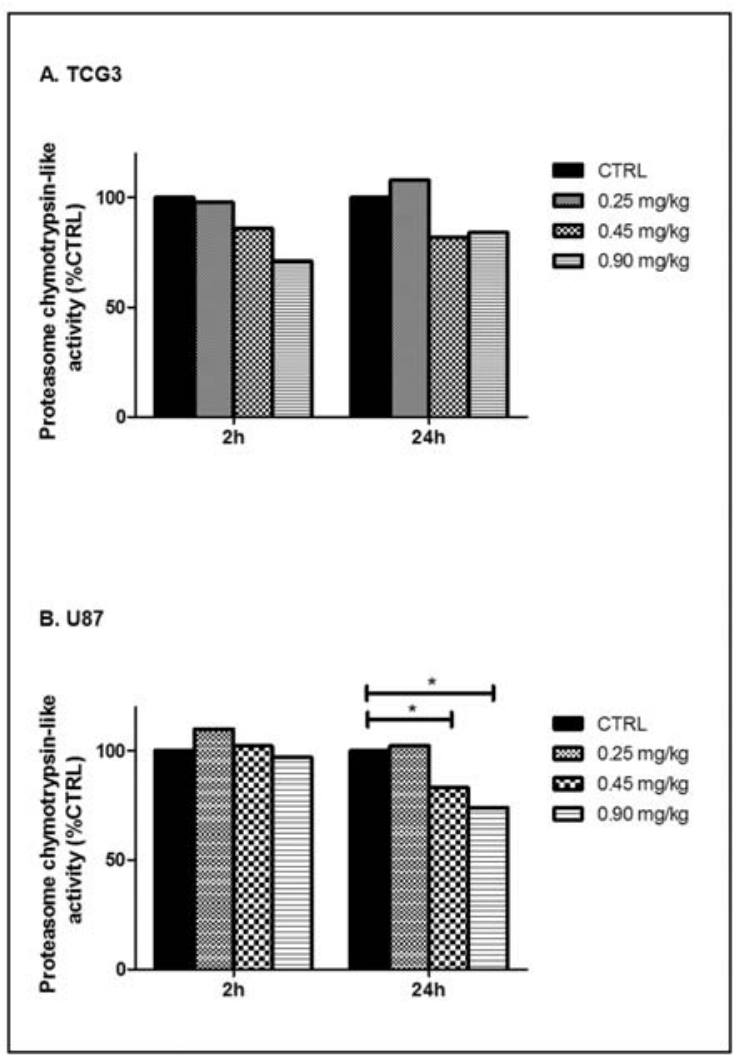

Figure 1. Effect of bortezomib on proteasome chymotrypsin-like activity in TCG3 (A) and U87 (B) xenografts. Activity was assessed 2 and 24 h after i.v. bortezomib administration by a fluorimetric assay. Results are expressed as a median activity of at least four tumors per treatment group; ${ }^{*} \mathrm{p}<0.05$.

a fluorescence plate reader (Safas, Monaco) with an excitation filter of $380 \mathrm{~nm}$ and an emission filter of $460 \mathrm{~nm}$.

Cell cycle distribution. Cell cycle distribution was determined by DNA content analysis after propidium iodide staining. Briefly, tumor samples were incubated with trypsin $(0.03 \mathrm{mg} / \mathrm{ml})$ and were dissociated using a Potter pestle. Samples were then treated with RNase A $(0.1 \mathrm{mg} / \mathrm{ml})$ and incubated with propidium iodide $(0.4 \mathrm{mg} / \mathrm{ml})$ for $30 \mathrm{~min}$ in the dark. Before cytometry, samples were filtered on a nylon mesh. An analysis of cell cycle distribution was performed using a FACSCalibur flow cytometer equipped with CellQuest and ModFit LT software (Becton-Dickinson, Heidelberg, Germany).

Proliferation and apoptosis determination. Proliferation and apoptotic indices were determined by immunohistochemistry as previously described (13). Briefly, $24 \mathrm{~h}$ after bortezomib treatment, tumors were excised and immediately fixed in

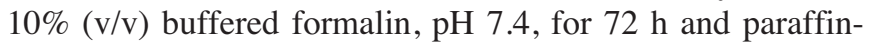
embedded. Serial coronal $5 \mu \mathrm{m}$ sections were cut through the center of the xenografts. Proliferation and apoptotic indices were measured on sections stained either with a speciesunspecific rabbit monoclonal antibody (clone SP6, Lab vision Corporation, Westinghouse, USA; diluted 1:100) to the cell cycle-associated antigen Ki-67, or with an anti-cleaved caspase- 3 rabbit anti-serum (BD Biosciences, Franklin Lakes, USA; diluted 1:1000) and the percentage of positively- 
A. TCG3

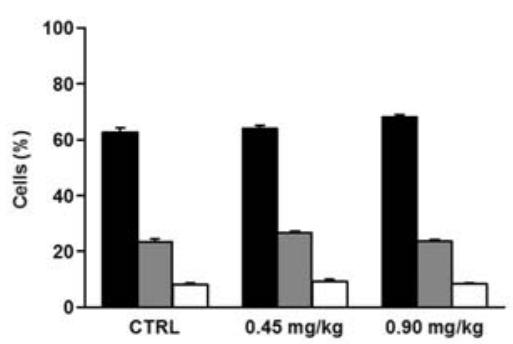

C. Proliferative index

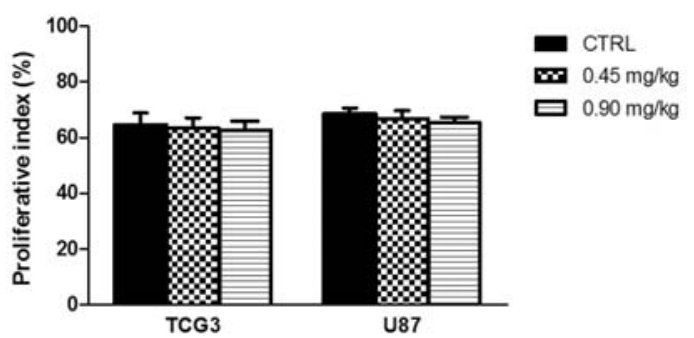

B. 487
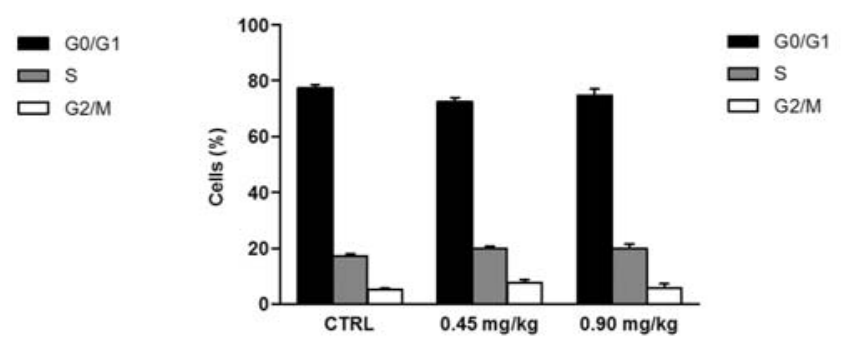

Figure 2. Effect of bortezomib on tumor proliferation and cell cycle distribution. (A and B) Cell cycle analysis in TCG3 (A) and U87 (B) xenografts. Cell cycle distribution was analyzed $24 \mathrm{~h}$ after the bortezomib injection. Cell cycle was assessed by propidium iodide staining and flow cytometry. For each treatment, the percentage of cells in the $\mathrm{G} 0 / \mathrm{G} 1, \mathrm{~S}$, or $\mathrm{G} 2 / \mathrm{M}$ phase of the cell cycle indicated is the mean distribution $( \pm \mathrm{SD})$ of at least 4 tumors. (C) The proliferative index corresponds to the percentage of tumor cells positively labeled for Ki-67 and was determined $24 \mathrm{~h}$ after the bortezomib injection. A minimum of 1000 tumor cells was counted for each tumor. For each treatment group, results are expressed as the mean apoptotic index ( \pm SD) of at least 4 tumors.

labeled tumor cells for at least 1000 counted tumor cells was recorded in independent areas of the main tumor masses which were free of necrosis. Antigen retrieval was carried out with a 2100 Proteogenix Retriever (Proteogenix, Fegersheim, France) following the manufacturer's instructions. Primary antibodies were applied for $16 \mathrm{~h}$ at $4^{\circ} \mathrm{C}$. Detection of the tissue-bound primary antibodies was performed using the biotinylated antibody/streptavidin-peroxidase detection system. Bound peroxidase was identified using the Novared ${ }^{\mathrm{TM}}$ detection system.

Antitumor effect of bortezomib. To follow tumor growth, tumor volume was determined three times per week. Two perpendicular diameters were measured with a caliper, and the tumor volume $\left(\mathrm{V}\right.$ in $\left.\mathrm{mm}^{3}\right)$ was calculated as $\mathrm{V}=\left(\right.$ length $\mathrm{x}$ width $\left.{ }^{2}\right) / 2$. Tumor volumes were recorded until tumors reached 3 times their initial volume $(3 \times \mathrm{V} 0)$.

Statistical analysis. Statistical analysis was performed using GraphPad 5.0 software. For each parameter analyzed, treated and non-treated tumors were compared using the nonparametric Mann-Whitney U test. Differences were considered significant at $\mathrm{p}<0.05$.

\section{Results}

Bortezomib effects on proteasome chymotrypsin-like activity. To explore the impact of bortezomib on its target, the proteasome chymotrypsin-like activity was assessed 2 and $24 \mathrm{~h}$ after the i.v. administration of bortezomib in TCG3 and U87-bearing mice. The different doses tested were: 0.25 , 0.45 and $0.90 \mathrm{mg} / \mathrm{kg}$ (Fig. 1).

Our results showed that bortezomib induced a dosedependent inhibition of proteasome activity in the two glioma models. In TCG3 xenografts (Fig. 1A), proteasome chymotrypsin-like activity was decreased to the same extent (20-30\% of basal proteasome activity) 2 and $24 \mathrm{~h}$ after the treatment of mice receiving either 0.45 or $0.90 \mathrm{mg} / \mathrm{kg}$. In U87 tumors (Fig. 1B), bortezomib did not modify the proteasome chymotrypsin-like activity $2 \mathrm{~h}$ after the injection. In contrast, bortezomib led to a significant $20-30 \%$ inhibition of the proteasome activity $24 \mathrm{~h}$ after drug injection using 0.45 and $0.90 \mathrm{mg} / \mathrm{kg}$ doses $(\mathrm{p}=0.026$ and 0.005 , respectively). Thus, bortezomib reached its target and inhibited it on the two models used.

Bortezomib effects on cell cycle distribution and proliferation index. To explore the impact of bortezomib in vivo, we evaluated the consequences of proteasome inhibition on cell cycle distribution assessed by flow cytometry after propidium iodide staining in our two glioma models. Our results showed that bortezomib did not modify distribution in the cell cycle in TCG3 and U87 xenografts (Fig. 2A and B). For example, in the TCG3 model, percentages of cells in the G2/M phase were $8.2 \pm 0.4$ vs. $8.3 \pm 0.4 \%$ for CTRL and BTZ at $0.90 \mathrm{mg} / \mathrm{kg}$, respectively. 


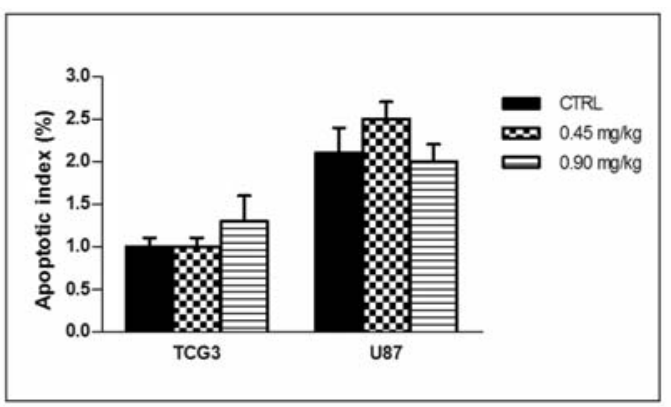

Figure 3. Effect of bortezomib on the apoptotic index of TCG3 and U87 glioma models. The apoptotic index corresponds to the percentage of tumor cells positively labeled for cleaved caspase- 3 and was determined $24 \mathrm{~h}$ after the bortezomib injection. A minimum of 1000 tumor cells was counted for each tumor. For each treatment group, results are expressed as the mean apoptotic index $( \pm \mathrm{SD})$ of at least 4 tumors.

We examined the effect of bortezomib on the proliferative index, determined by immunohistochemical detection of the cell cycle-associated antigen $\mathrm{Ki}-67$. Our results demonstrated that the two glioma models used presented a similar proliferative index (Fig. 2C). In the TCG3 model, 64.8 $44.1 \%$ cells were positively stained for $\mathrm{Ki}-67$ and the proliferative index for U87 tumors was $68.6 \pm 2.0 \%$. Bortezomib had no significant effect on cell proliferation within $24 \mathrm{~h}$ following a single i.v. injection at 0.45 or $0.90 \mathrm{mg} / \mathrm{kg}$. For example, at the dose of $0.90 \mathrm{mg} / \mathrm{kg}$, proliferative indices in bortezomib-receiving mice were $62.7 \pm 3.2 \%$ for the TCG3 model and $65.4 \pm 2.0 \%$ for U87 xenografts.

Bortezomib did not induce apoptosis on glioma models. The apoptotic index was determined $24 \mathrm{~h}$ after the bortezomib injection by immunohistochemical detection of the cleaved caspase-3.

TCG3- and U87-untreated xenografts showed a limited apoptotic index of $1.0 \pm 0.1$ and $2.1 \pm 0.3 \%$, respectively (Fig. 3). Our results demonstrated that bortezomib did not induce any enhancement in the apoptotic index on either TCG3 nor U87 glioma models. For example, in tumors treated with a dose of $0.90 \mathrm{mg} / \mathrm{kg}$, the apoptotic index was only $1.3 \pm 0.3$ and $2.0 \pm 0.2 \%$ for TCG3 and U87 xenografts, respectively.

Bortezomib did not reduce tumor growth in vivo. To explore the antitumor effect of bortezomib, it was administered at the highest tested dose of $0.90 \mathrm{mg} / \mathrm{kg}$ to tumor-bearing mice. Tumor growth was followed three times per week until the tumors reached 3 times their initial volume (Fig. 4).

In the CTRL groups, the mean times to reach $3 \mathrm{~V} 0$ were $7.0 \pm 0.9$ and $11.9 \pm 1.5$ days for TCG3 and U87 models, respectively. In the two models, BTZ did not present any antitumor effect and the mean times to reach $3 \mathrm{~V} 0$ were $8.6 \pm 1.6$ and $13.8 \pm 0.9$ days for TCG3 and U87, respectively. The difference with CTRL groups did not reach the level of statistical significance.

\section{Discussion}

Proteasome inhibitors represent a new group of cytotoxic agents that target the $20 \mathrm{~S}$ proteasome, a component of the

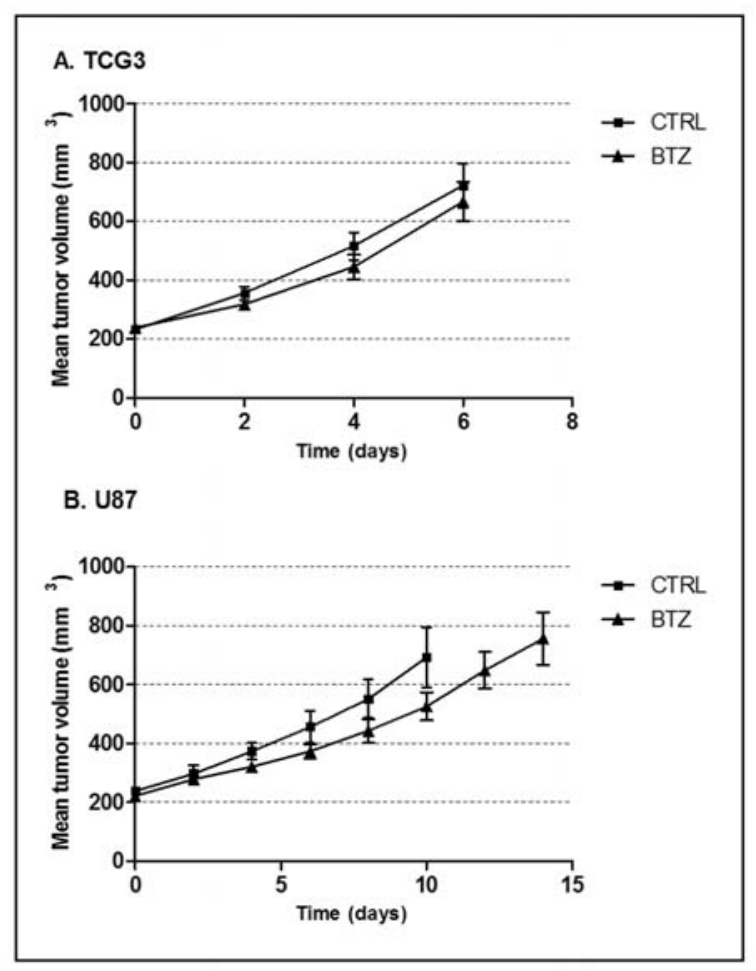

Figure 4. Effect of bortezomib on TCG3 (A) and U87 (B) growth. Tumorbearing mice were randomly assigned in the two groups of CTRL (TCG3 model $\mathrm{n}=9$ and U87 model $\mathrm{n}=7$ ) and BTZ (TCG3 model $\mathrm{n}=9$ and U87 model $\mathrm{n}=10$ ). Treatments began when tumor volume reached $250 \pm 50 \mathrm{~mm}^{3}$ (V0). BTZ was injected (i.v.) at the dose of $0.90 \mathrm{mg} / \mathrm{kg}$ on D0. Tumor volume was measured three times per week. For each treatment group, results are expressed as the mean tumor volume $( \pm \mathrm{SD})$ evolution.

ubiquitin-proteasome complex responsible for the degradation of unwanted cellular proteins $(3,5)$. Although the mechanism by which proteasome inhibitors kill neoplastic cells is not well defined, these molecules are potent apoptotic inducers and their antitumor potential has been reported in a wide variety of tumors $(8,14,15)$. Moreover, the clinical results of bortezomib in multiple myeloma provided proof of concept for proteasome inhibition as an anticancer approach and have prompted the investigation of this drug in other malignancies. However, only a few studies are available concerning the effect of bortezomib on glioma cells, each of them being realized on established glioma cell lines and/or primary glioblastoma explants. These studies have demonstrated that as with other proteasome inhibitors, bortezomib is able to induce apoptosis in glioma cell lines in vitro $(9,10,16-18)$. To our knowledge, preclinical studies using bortezomib on in vivo brain tumor models have yet to be reported on.

In the present study, we investigated the effect of bortezomib in vivo on two human malignant glioma models. We selected $0.90 \mathrm{mg} / \mathrm{kg}$ as the highest dose tested, since it corresponds to the weekly clinical dose of bortezomib administered in the treatment of multiple myeloma patients, i.e. $2.6 \mathrm{mg} / \mathrm{m}^{2}$ (14). Our study demonstrates that bortezomib administered at this clinically relevant dose did not present any antitumor effect on glioma models.

Considering the effects of bortezomib on its target, our results showed that bortezomib was able to reduce the 
proteasome chymotrypsin-like activity of $\sim 30 \%$ of basal activity in the $24 \mathrm{~h}$ following the injection of $0.90 \mathrm{mg} / \mathrm{kg}$ for the two models studied. Comparable levels of proteasome inhibition in vivo have already been reported for other tumors treated with similar doses of bortezomib. For example, using a multiple myeloma model xenografted into nude mice, LeBlanc et al have reported that bortezomib (1 $\mathrm{mg} / \mathrm{kg}$ i.v.) was able to inhibit $35 \%$ of the proteasome chymotrypsin-like activity in tumors and induced an apoptotic response and a tumor growth delay, as compared to untreated tumors (19). Thus, the cellular consequences of partial proteasome inhibition appear to be cell-type dependent, although a similar proteasome inhibition did not affect myeloma and glioma cells to the same extent, since bortezomib was clearly unable to induce apoptosis in our glioma models. Moreover, we showed that bortezomib had no effect on the proliferative index and cell cycle distribution.

Our results are in contrast with those from Yin et al (10), who have demonstrated that $\sim 15 \%$ of U87 cells became apoptotic when cultured for $48 \mathrm{~h}$ with bortezomib. These authors have demonstrated that bortezomib induced a G2/M cell cycle arrest and the percentage of cells in the G2/M phase increased $\sim 2$-fold after their exposure to bortezomib for $24 \mathrm{~h}$. Moreover, Styczynski et al (9) demonstrated that the two glioblastoma cell lines showed good sensitivity to bortezomib, as compared to an acute lymphoblastic leukemia cell line.

The discrepancy between our in vivo results and the relatively promising in vitro data obtained by others can be explained by several methodological findings. In the study of Styczynski et al (9), the efficacy of BTZ is compared to that obtained for leukemia culture cells using drugs essentially active against leukemia rather than glioma. The choice of the tumor model used may explain the discrepancies observed between our study and other published data. Studies have undertaken to report on established glioma cell lines in cell culture assays. In spite of the great insights offered by these types of models, established tumor cell lines poorly represent the cellular heterogeneity observed in tumors. In contrast, xenograft models, constituted by tumoral and stromal cells, are closer to the original tumor from which they are derived $(20,21)$. Tumor cells from our xenografts are poorly exposed to bortezomib to the same extent as cells grown in monolayer cultures and to our knowledge, the effects of bortezomib on proteasome chymotrypsin-like activity in glioma cell cultures have yet to be reported on. It is thus possible that our xenografts did not receive a sufficient dose of bortezomib to present similar patterns of cell cycle distribution and apoptosis to those obtained in vitro.

Finally, the results presented in this study do not support the use of bortezomib in the treatment of high-grade gliomas. Our results, contrary to data obtained from in vitro studies, emphasize the importance of performing preclinical studies using in vivo tumor models, before initiating clinical studies.
Cancer ${ }^{6}$ for financial support. We thank Dr L. Bolotine and S. Marchal (CAV CRAN UMR 7039 CNRS, Nancy University, Vandoeuvre-les-Nancy) for their assistance with fluorimetry and flow cytometry.

\section{References}

1. Stupp R, Mason WP, van den Bent MJ, et al: Radiotherapy plus concomitant and adjuvant temozolomide for glioblastoma. $\mathrm{N}$ Engl J Med 352: 987-996, 2005.

2. Ohgaki $\mathrm{H}$ and Kleihues P: Epidemiology and etiology of gliomas. Acta Neuropathol 109: 93-108, 2005.

3. Glickman $\mathrm{MH}$ and Ciechanover A: The ubiquitin-proteasome proteolytic pathway: destruction for the sake of construction. Physiol Rev 82: 373-428, 2002.

4. Mani A and Gelmann EP: The ubiquitin-proteasome pathway and its role in cancer. J Clin Oncol 23: 4776-4789, 2005.

5. Ludwig H, Khayat D, Giaccone G and Facon T: Proteasome inhibition and its clinical prospects in the treatment of hematologic and solid malignancies. Cancer 104: 1794-1807, 2005.

6. Mitsiades CS, Mitsiades N, Hideshima T, Richardson PG and Anderson KC: Proteasome inhibition as a therapeutic strategy for hematologic malignancies. Expert Rev Anticancer Ther 5: 465-476, 2005.

7. Kane RC, Farrell AT, Sridhara R and Pazdur R: United States Food and Drug Administration approval summary: bortezomib for the treatment of progressive multiple myeloma after one prior therapy. Clin Cancer Res 12: 2955-2960, 2006.

8. Adams J, Palombella VJ, Sausville EA, et al: Proteasome inhibitors: a novel class of potent and effective antitumor agents. Cancer Res 59: 2615-2622, 1999.

9. Styczynski J, Olszewska-Slonina D, Kolodziej B, Napieraj M and Wysocki M: Activity of bortezomib in glioblastoma. Anticancer Res 26: 4499-4503, 2006

10. Yin D, Zhou H, Kumagai T, et al: Proteasome inhibitor PS-341 causes cell growth arrest and apoptosis in human glioblastoma multiforme (GBM). Oncogene 24: 344-354, 2005.

11. Chastagner P, Kozin SV and Taghian A: Topotecan selectively enhances the radio response of human small-cell lung carcinoma and glioblastoma multiforme xenografts in nude mice. Int $\mathbf{J}$ Radiat Oncol Biol Phys 50: 777-782, 2001.

12. Lightcap ES, McCormack TA, Pien CS, Chau V, Adams J and Elliott PJ: Proteasome inhibition measurements: clinical application. Clin Chem 46: 673-683, 2000.

13. Kremer S, Pinel S, Vedrine PO, et al: Ferumoxtran-10 enhancement in orthotopic xenograft models of human brain tumors: an indirect marker of tumor proliferation? J Neurooncol 83: 111-119, 2007.

14. Adams J, Elliott PJ and Bouchard P: Preclinical development of bortezomib (VELCADE ${ }^{\mathrm{TM}}$ ). In: Proteasome Inhibitors in Cancer Therapy. Adams J (ed). Totowa, NJ, pp233-269, 2004.

15. Dou QP and Li B: Proteasome inhibitors as potential novel anticancer agents. Drug Resist Updat 2: 215-223, 1999.

16. Kitagawa H, Tani E, Ikemoto H, Ozaki I, Nakano A and Omura S Proteasome inhibitors induce mitochondria-independent apoptosis in human glioma cells. FEBS Lett 443: 181-186, 1999.

17. Wagenknecht B, Hermisson M, Eitel K and Weller M: Proteasome inhibitors induce p53/p21-independent apoptosis in human glioma cells. Cell Physiol Biochem 9: 117-125, 1999.

18. Legnani FG, Pradilla G, Thai QA, et al: Lactacystin exhibits potent anti-tumor activity in an animal model of malignant glioma when administered via controlled-release polymers. J Neurooncol 77: 225-232, 2006.

19. LeBlanc R, Catley LP, Hideshima T, et al: Proteasome inhibitor PS-341 inhibits human myeloma cell growth in vivo and prolongs survival in a murine model. Cancer Res 62: 4996-5000, 2002.

20. Frese KK and Tuveson DA: Maximizing mouse cancer models. Nat Rev Cancer 7: 654-658, 2007.

21. Rich JN: Cancer stem cells in radiation resistance. Cancer Res 67: 8980-8984, 2007

\section{Acknowledgements}

We are grateful to the French 'Ligue Contre le Cancer, Comités Lorrains' and 'Association pour la Recherche sur le 